\title{
Questes
}

vestes Revue pluridisciplinaire d'études médiévales

9 | 2006

À la marge

\section{À la marge : conclusion}

\section{Sophie Albert}

\section{(2) OpenEdition}

Journals

Édition électronique

URL : http://journals.openedition.org/questes/2069

DOI : 10.4000/questes.2069

ISSN : 2109-9472

\section{Éditeur}

Les Amis de Questes

\section{Édition imprimée}

Date de publication : 15 juin 2006

Pagination : 64-66

ISSN : 2102-7188

\section{Référence électronique}

Sophie Albert, « À la marge : conclusion », Questes [En ligne], 9 | 2006, mis en ligne le 01 janvier 2014, consulté le 15 septembre 2020. URL : http://journals.openedition.org/questes/2069 


\title{
Conclusion
}

\author{
Sophie ALBERT
}

« A la marge » : la formule invitait à réfléchir aux contenus, aux enjeux et aux sens d'un espace particulier, celui des marginalia aussi bien que des gloses, de pays des confins peuplés souvent, dans l'imaginaire médiéval, par les figures les plus déconcertantes de «l'autre » sous toutes ses formes. La notion de marge impliquait un présupposé : être en mesure de définir un centre, par rapport auquel il n'est pas de marge possible; de définir, aussi, les procédés de différenciation entre les deux espaces. Cette différenciation passe par une nécessaire disjonction dont il s'agit, au-delà du simple constat d'une séparation spatiale, de préciser les modalités. Disjonction à la fois linguistique, rythmique et visuelle, dans le manuscrit vénitien qu'étudie Amandine Mussou: les commentaires marginaux des Echecs amoureux sont tout à la fois rédigés en latin et en prose, quand le texte est composé en vers et en français. Disjonction morale, sociale et religieuse dans les textes analysés par Julien Abed, Pierre Levron et Sophie Albert, qui mettent en évidence un décalage entre un univers normatif et des personnages ou des royaumes qui contreviennent à ses lois. Ainsi, la Sibylle d'Antoine de la Sale vit dans un emboîtement d'espaces marginaux - marche d'Ancône, mont, forêt, grotte -, et elle est en même temps païenne, orgiaque et diabolique ; les chevaliers criminels se montrent tour à tour cruels, anti-courtois, violents ou monstrueux ; le Northumberland du « roman de Guiron » met à mal aussi bien les frontières entre mensonge et vérité que les règles lignagères et le système vindicatoire. Dans tous ces exemples, la marginalité se construit par surenchère, par une accumulation de traits distinctifs. 
A cette construction positive fait pendant une marginalisation négative, où la mise à la marge se dit par une sorte de « défaut d'être ». Le Chaitivel, comme le montre Vanessa Obry, ne parvient pas à s'individualiser en tant que personnage héroïque, demeurant à la marge de la désignation; d'après Sophie Poitral, l'ermite de René d'Anjou est réduit à n'être qu'un type privé de toute fonction spirituelle. La marginalité des deux personnages passe par une absence de qualification positive : tous deux demeurent en deçà des potentialités des types qu'ils incarnent, le bellator et l'orator.

Comme le suggèrent les différentes représentations du Northumberland, les significations que revêtent les marges s'expliquent, dans une certaine mesure, par la poétique ou la logique générales des textes dans lesquelles elles s'inscrivent. A un Northumberland défini par son rapport au merveilleux correspondent le Merlin, sa Suite et le Lancelot propre, romans dans lesquels la magie tient encore une place non négligeable ; à un Northumberland caractérisé par ses écarts moraux et juridiques correspond le « roman de Guiron », dans lequel la merveille a cédé la place à une rationalisation extrême et à un intérêt certain pour les enjeux sociaux du discours littéraire. Aussi, la marge, qu'elle reçoive une définition positive ou négative - qu'elle soit exprimée, pour reprendre les mots de Vanessa Obry, en terme d'exception ou d'exclusion -, entre en résonance avec un projet auctorial engageant l'ensemble de l'œuvre. Amandine Mussou l'a montré, qui rattache les commentaires marginaux du manuscrit de Venise à l'élaboration d'un système interprétatif global ; Vanessa Obry également, sous un angle assez différent : de même que Marie de France présente chacun de ses lais comme un récit en fabrication, de même le personnage du Chaitivel reste à jamais en passe d'accéder à la référence, inachevé comme l'écriture du poème. Dans une perspective similaire, l'ermite de Sophie Poitral, en deçà des virtualités fonctionnelles qu'offraient les ermites de la Queste del saint Graal, illustre les modalités de la réécriture dans le Livre 
du Cuer d'amour espris: René d'Anjou vide de leur substance les types hérités du roman arthurien pour la transférer aux types issus de la fiction allégorique.

Ces correspondances trouvent leur meilleure preuve dans un paradoxe : certains éléments à première vue marginaux occupent en même temps une place centrale. Le Chaitivel du lai et la Sibylle d'Antoine de la Sale, tout en étant, par certains aspects, mis à la marge, sont les principaux protagonistes des textes qui les mettent en scène - le lai le dit assez, en se donnant pour titre le nom du personnage. De cette dialectique entre centre et périphérie ${ }^{1}$, la contribution d'Amandine Mussou propose une application particulièrement éloquente : dans le manuscrit de Venise, la marge, délibérément, est intégrée au milieu de la page pour délivrer le sens caché du récit. Quant aux textes de Jean Froissart et d'Antoine de la Sale, s'ils représentent des marges hyperboliques - Sibylle outrancière et Northumberland saturé de merveilles -, c'est pour aussitôt mettre à distance leur marginalité : la déclarer factice ou révolue et, dans les deux cas, la nier.

\footnotetext{
${ }^{1}$ Les personnes ayant fait leurs classes de géographie dans les années 1990 reconnaîtront sans peine dans cette expression le titre de leur chapitre préféré...
} 